\title{
Analysis of thermal comfort in education building in surveys
}

\author{
Agata Witkowska ${ }^{1}$, and Katarzyna Gładyszewska-Fiedoruk ${ }^{2, *}$ \\ ${ }^{1}$ Bialystok University of Technology, student \\ ${ }^{2}$ Bialystok University of Technology, Department of HVAC Engineering, 15-351 Białystok, Poland
}

\begin{abstract}
Main parameters of indoor air quality could influence people health and ability to work and ability to learning. The research was conducted in University of Technology building located in Białystok, north-eastern Poland. Research - surveys was devoted to issues related to the thermal comfort in a classroom of university. Interviewees declared perceptible temperature and described their feelings connected to the temperature sensation. Other indoor parameters were also analysed such as: temperature, humidity and indoor air quality and noise level. Peoples - students filled the surveys about thermal comfort and indoor parameters. The research included indoor thermal comfort.
\end{abstract}

\section{Introduction}

Thermal comfort is the condition of the organism, in which person feels, that his body is in state of thermal equilibrium. If there is thermal comfort in the room, people does not feel neither a warmth nor a coldness. In addition, thermal comfort means, that there is no undesirable heating or cooling of individual parts of the body, for example heating legs by the heat from too warm floor or cooling of the head by drafts. The feeling of thermal comfort is an individually and subjectively felt $[1,2]$.

Surveys are therefore necessary to determine thermal comfort, which is an individual and subjective feeling.

Surveys that present the subjective perception of thermal internal conditions do not fully reflect the concept of thermal comfort. According to the authors of the publications [3, 4], reference should be made to the objective conditions prevailing in the room. It is therefore necessary to simultaneously measure air parameters like temperature, humidity, air velocity, and noise level in the room [5].

Many researchers have dealt with the topic of thermal comfort [4, 6, 7]. Various types of rooms were analyzed. Among others the residential buildings [4, 8], the classrooms [9-11], office buildings [6] and preschools [7, 12] were examined. The tests of air parameters were also conducted in car cabins [13, 14], where is mechanical ventilation and pollution, which is caused by the presence of people, just like in didactic rooms. However, the difference is enormous - the number of air exchanges per hour will never be the same in car cabins and in classrooms.

\footnotetext{
*Corresponding author: k.gladyszewska@pb.edu.pl
} 
There is a connection between the energy standard of the building and thermal comfort [6], [8], [15-20]. It means, that maintaining the appropriate thermal comfort affects on operating cost of a building. What is more, keeping thermal comfort Has an impact on human health. That is why the analysis of this issue is so important.

\subsection{Analysed air parameters}

In this research analysed air parameters determining the thermal comfort was the temperature, humidity and indoor air quality like concentration of carbon dioxide and noise in public buildings, including education buildings like a university classrooms.

WHO [21] recommend the following air parameters in human dwelling places: temperature (depending on the type of human activity) in the range of $18-24^{\circ} \mathrm{C}$, humidity between 40 and $60 \%$, carbon dioxide concentration up to $1000 \mathrm{ppm}$.

The best feeling of thermal comfort is provided by the temperature in the range of $20-24^{\circ} \mathrm{C}$, depending on the season. In winter, the temperature closer the lower limits of this range is tolerated better, while in the summer the human body tolerates higher temperatures well. These values are in accordance with PN-EN 13779 [22].

Relative humidity is closely related to the air temperature. It informs what is the moisture content in the air at a given temperature in relation to the moisture content that would cause condensation. It means that the same amount of water in the form of vapor diluted in the air will be another relative humidity at different temperatures.

The perception of the surrounding environment is also affected for example by noise, whose long-term impact causes the general exasperation.

The noise it causes irritability, fatigue and fatigue of the whole body, especially of a hearing. The noise has a negative action on the human health. The noise in education buildings in standards is $40 \mathrm{~dB}$ [23-25].

\subsection{Surveys}

The results of the surveys allow to get to know the subjective feeling of people, who filling them. Sometimes, the survey is the only reconnaissance tool $[8,26]$. In the thermal comfort analysis, surveys are often used in research [7, 19, 27].

In this article there are presented the individual and subjective results of the surveys filled by students in didactic rooms during the classes. The room has mechanical ventilation. These results were related to the measurements of internal air parameters made with the use of gauges.

\section{Methodology}

The education building is located in city Bialystok, in north-eastern Poland, in eastern Europe in the temperate zone. Analysed education building is University of Technology, Faculty of Civil Engineering and Environmental Engineering (fig. 1). Analysed classroom present figure 2 . 


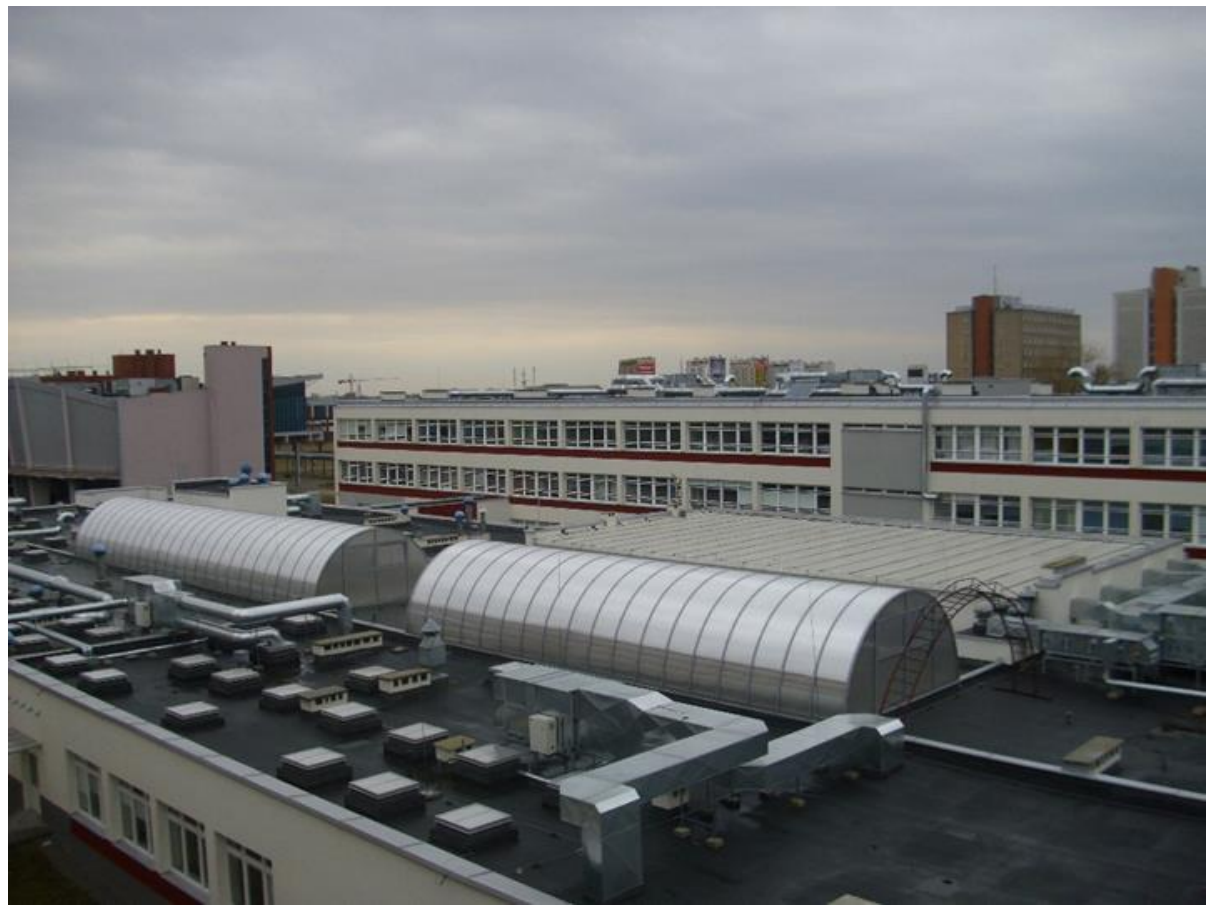

Fig. 1. Analysed education building.

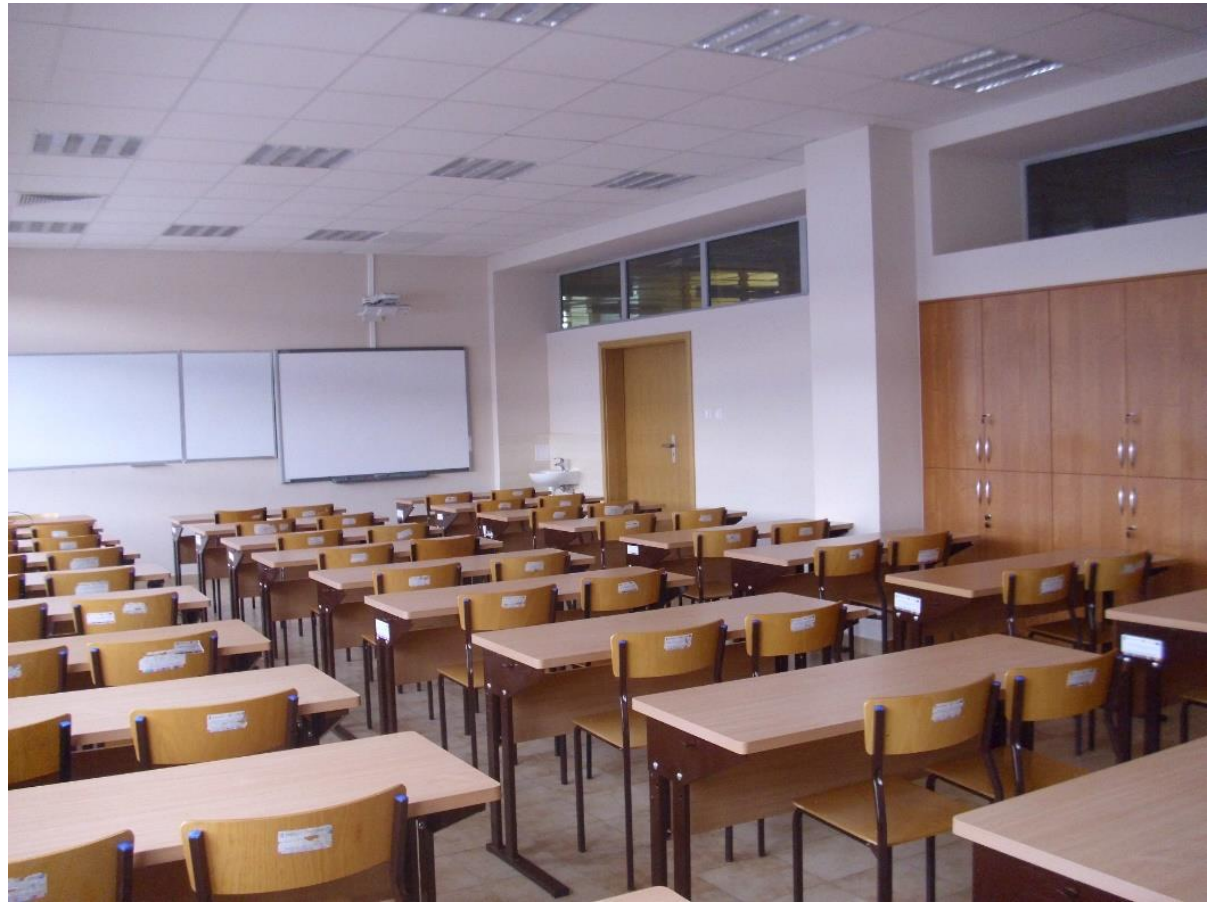

Fig. 2. Analyzed classroom.

The presented survey was created for the own needs of experimental research of thermal comfort in didactic rooms. While writing the survey, publications are used [8, 26]. 
The research was conducted in the studied classrooms was recorded with classes in progress. Classes are 45 minutes long. In analyzed classroom during measurements there were 30 persons. The measurements air parameters were performed using a Testo 435-4 recorder equipped with an IAQ probe and for the measurement of sound were using measuring instrument Testo 81505638155 . For all measurements located $0.8 \mathrm{~m}$ above the floor at five room points and then average values were calculated.

During our research students taking part in classes filled surveys on their comfort. 15 women and 15 men participated in our tests, fulfilled questionnaires. They judged their comfort as "satisfied", "neutral" or "dissatisfied" at the end of the didactic class.

The questionnaire consisted of the following questions:

1. How is thermal comfort assessed? Is "glad", "neutral" or "dissatisfied".

2. How is the degree of humidity assessed? Is "very glad", "glad", "no opinion", "dissatisfied", "very dissatisfied".

3. How is the air temperature assessed? Is "very glad", "glad", "no opinion", "dissatisfied", "very dissatisfied".

4. How is the noise level assessed? Is "very glad", "glad", "no opinion", "dissatisfied", "very dissatisfied".

5. You feel the air temperature is: too hot, warm, ok, cold, too cold.

6. You feel degree of humidity is: too high, high, ok, dry, too dry.

7. You feel the noise level is: too loud, loud, ok, quietly, too quiet.

They were not asked about age and sex, because all participants were 22-23 years old and there were 15 women and 15 men in the room during the study.

\section{Results and discussion}

In analyzed classroom during experiment, indoor air temperature was recorded in range from $23.1^{\circ} \mathrm{C}$ to $24.9^{\circ} \mathrm{C}$ it was too high. Relative humidity was in range $31.7 \%-38.3 \%$ was so low. Noise level was usually under $40 \mathrm{~dB}$ was suitable [21, 22].

At the end of the didactic class students answered seven questions about their feelings. The results of the survey are presented in figures 3 .

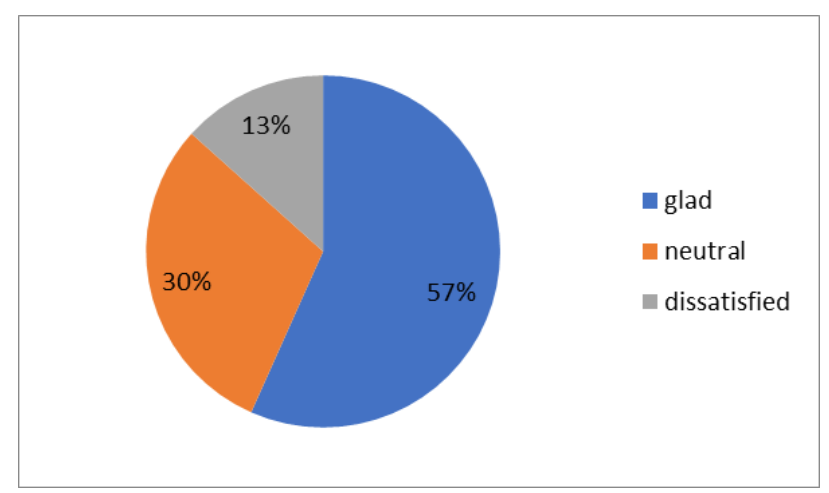

Fig. 3. How is thermal comfort assessed?

Most students felt that thermal comfort of the classroom during the experiment was glad $-57 \%$ and neutral $-30 \%$. Only $13 \%$ students felt that thermal comfort was dissatisfied (fig. $3)$. When assessing thermal comfort most students felt that humidity was glad $(27 \%)$ and very glad (47\%) (fig. 4), but evaluating the humidity without the context of thermal comfort students felt that humidity was ok (77\%) (fig. 6). 


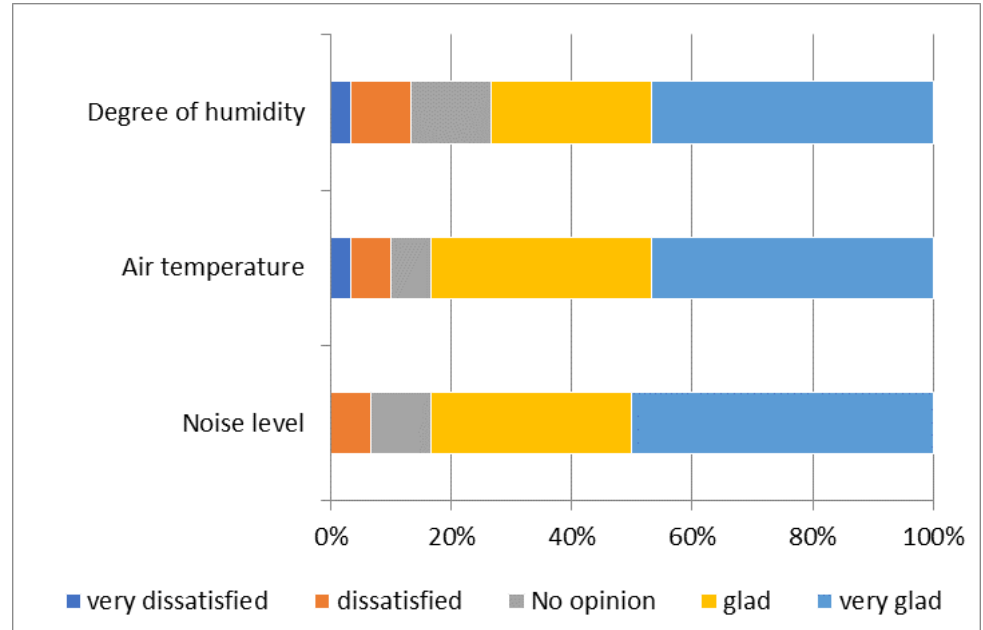

Fig. 4. How is degree of humidity, the air temperature, the noise level assessed?

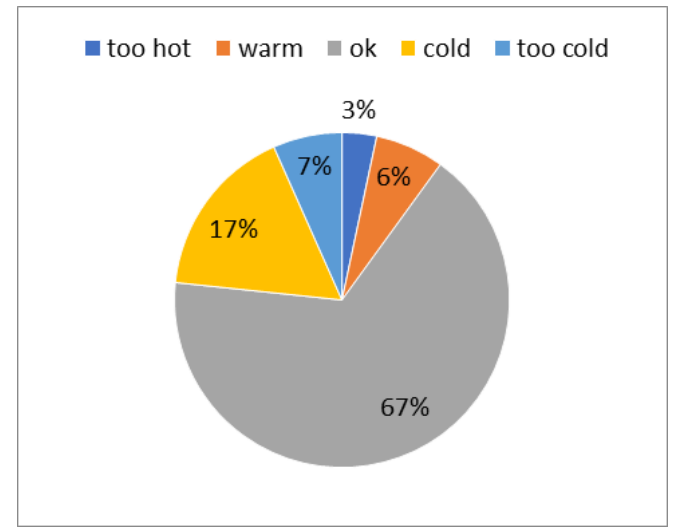

Fig. 5. You feel the air temperature is: too hot, warm, ok, cold, too cold.

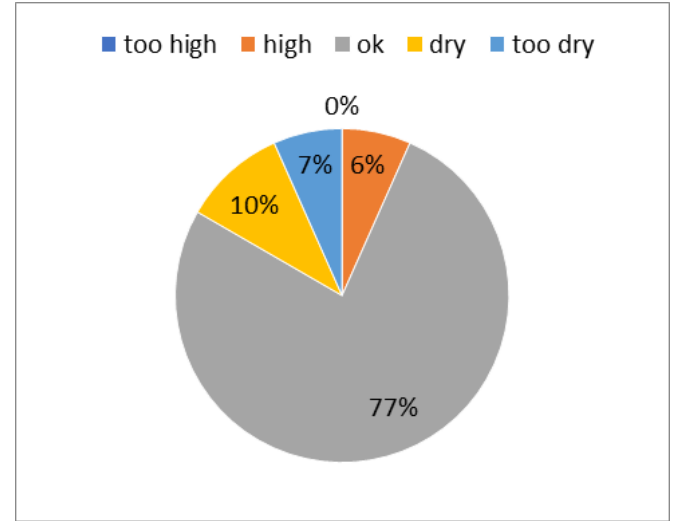

Fig. 6. You feel degree of humidity is: too high, high, ok, dry, too dry. 


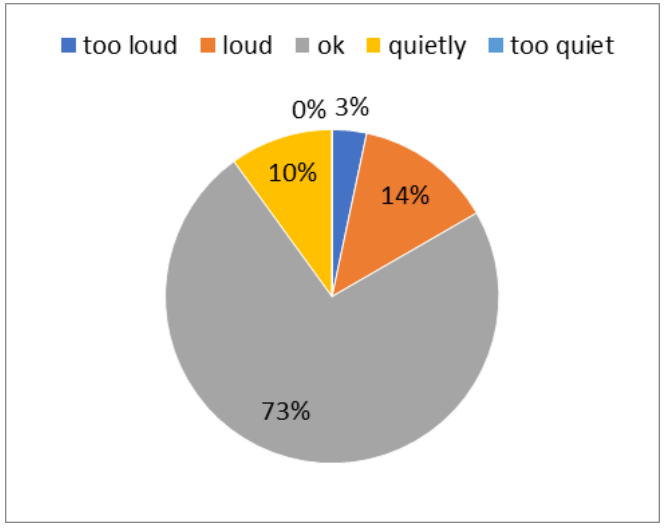

Fig. 7. You feel the noise level is: too loud, loud, ok, quietly, too quiet.

When assessing thermal comfort most students felt that the air temperature was glad (37\%) and very glad (47\%) (fig. 4), but evaluating the air temperature without the context of thermal comfort students felt that the air temperature was ok (67\%) (fig. 5). When assessing thermal comfort most students felt that the noise level was glad (33\%) and very glad (50\%) (fig. 4), but evaluating the noise level without the context of thermal comfort students felt that the noise level was ok (73\%) (fig. 7).

The results of the analysis coincide with the results presented in the literature [9-11]. It is surprising that on another, much smaller group of surveyed and in other external conditions, the results are similar to each other.

\section{Conclusion}

The results of measurements and studies allowed to analyze thermal comfort in classroom in education building.

The results of the experiment were related with subjective comfort perception of students.

Most students felt that temperature of the classroom during the experiment was suitable (77\%). The majority of students $(73 \%)$ found humidity as acceptable. The noise level most students felt ok. This is very important because, not proper noise level noise has a negative impact on the health of the person.

This scientific project was financed within the project VIPSKILLS (Virtual and Intensive Course Developing Practical Skills of Future Engineers) program of Erasmus+ (KA203) and program of scientific cooperation "The possibility of the renewable energy sources usage in the context of improving energy efficiency and air quality in buildings and civil constructions". This scientific project was financed within the framework of science research funds at Białystok University of Technology S/WBIIŚ/4/2014.

\section{References}

1. ASHRAE Thermal Environmental Conditions for Human Occupancy ASHRAE Standard 55, Atlanta, (2004)

2. P.O. Fanger, Komfort cieplny (Arkady, Warszawa, 1974)

3. A. Bogdan, M. Chludzinska, HVAC\&R Res. 16, 529-542, (2010)

4. K. Arendt, M. Krzaczek, J. Tejchman, Build. Simul. 10, 2, 229-238 (2017) 
5. ASHRAE Standard 62-2007, Ventilation for Acceptable Indoor Air Quality. American Society of Heating and Refrigerating and Air-Conditioning Engineers Inc, Atlanta (2007)

6. S.-Y. Lin, S.-C. Chiu, W.-Y. Chen, Energy Build. 86, 7-15 (2015)

7. M. Oliveira, K. Slezakova, C. Delerue-Matos, M.D.C. Pereira, S. Morais, J. Tox. Environ. Heal. Part A 80, 13-15, 740-755 (2017)

8. Z. Li, H. Yoshino, R. Shi, C. Zhang, Tongji University, Shanghai, China 14-15, 46-51 (2002)

9. A. Montazami, M. Gaterell, F. Nicol, M. Lumley, Ch. Thoua, Build. Environ. 122, 422-434 (2017)

10. V. Cardoso, N.M.M. Ramos, R.M.S.F. Almeida, E. Barreira, J. Poças Martins, M.L. Simes, L. Sanhudo, B. Ribeiro, Build. Environ. 126, 276-287 (2017)

11. Y. Li, Y. Yuan, Ch. Li, X. Han, X. Zhang, Build. Environ. 131, 53-62 (2018)

12. K. Gładyszewska-Fiedoruk, S. Jachimowicz, $10^{\text {th }}$ International Conference Environmental Engineering, Vilnius, Lithuania (2017)

13. M. Luangprasert, C. Vasithamrong, S. Pongratananukul, C. Sunhapos, P. Suree, I.P.D. De Silva, J. Air Waste Manage. Assoc. 67, 5, 623-633 (2017)

14. A. Szczurek, M. Maciejewska, Transport. Res. Part D: Transp. Environ. 48, 161-170 (2016)

15. Directive 2002/91/EC of European Parliament and the Council of 16 December 2002 on the Energy Performance of the Buildings (2002)

16. D.A. Krawczyk, Energy Procedia 95, 216-222 (2016)

17. D.A. Krawczyk, Pol. J. Environ. Stud. 24, 4, 1863-1866 (2015)

18. D.A. Krawczyk, K. Gładyszewska-Fiedoruk, Edited by: P. Hajek, J. Tywoniak, A. Lupisek, et al. Conference on Central Europe towards Sustainable Building (CESB13) Prague, Czech Republic, 555-558 (2013)

19. J. Mei, X. Xia, Appl. Energ. 195, 439-452 (2017)

20. A. Kviesis, A. Klavina, G. Vitols, Eng. Rural Dev. 16, 719-724 (2017)

21. WHO, Air Quality Guidelines for Europe, Second Edition, WHO Regional Office for Europe Copenhagen, European Series, No. 91 (2000)

22. PN-EN 13779:2008, Ventilation of residential buildings. Requirements for the properties of ventilation and air conditioning (2008)

23. PN-87/B-02151/02 Building acoustics. Noise protection facilities by weight of buildings. Allowable values sound level indoors (1987)

24. PN-B-02151-4:2015-06 Building acoustics. Protection against noise in buildings. Part 4: Requirements concerning the conditions of reverberation and speech intelligibility in spaces and research guidelines (2015)

25. S. Jachimowicz, K. Gładyszewska-Fiedoruk, eISSN 2029-7092/eISBN 978-609-476044-0, ID: enviro.2017.020, (2017). DOI: https://doi.org/10.3846/enviro.2017.020

26. Z. Lin, S. Deng, Energy Build. 38, 1302-1307 (2006)

27. A.L. Naumov, I.A. Tabunshchikov, D.V. Kapko, M.M. Brodach, Energy Build. 90, $1-5(2015)$ 